\title{
MORTALITY AMONG DIABETES IN-PATIENTS IN PORT-HARCOURT, NIGERIA
}

\author{
UNACHUKWU CN, UCHENNA DI, YOUNG E \\ Department of Medicine, University of Port Harcourt \\ Teaching Hospital, Port Harcourt, River State, Nigeria \\ Corresponding Author \\ Dr. Chioma N Unachukwu, \\ $B S c, M B B S, F W A C P$ \\ E-mail: chiomaunachukwu@yahoo.com
}

\begin{abstract}
Background: Diabetes mellitus is a major cause of mortality and morbidity among in-patients in Nigeria. It may result from the acute metabolic complications or from the inexorable effects of chronic complications in the major organ systems.

Objectives: This study was to determine the death rates and causes of death among in-patients with diabetes at an urban tertiary hospital in Port-Harcourt.

Materials and Methods: The medical records of patients admitted with diabetes mellitus into the medical wards of the University of Port Harcourt Teaching Hospital from 1995-2004 were reviewed. The sources of data were the ward admission, death registers, death certificates and medical records. The annual and overall fatality rates were calculated from the available data.

Results: During the period under review, 6,574 patients were admitted into the medical wards. Out of these, 686 (10.4\%) were due to diabetes and its complications. The diabetic patients comprised of 428 (62.4\%) males and 258 (37.6\%) females giving a M:F ratio of 1.7:1. One hundred and eighteen of the diabetic patients died giving a case fatality of $17.2 \%$. The main causes of death were diabetic ketoacidosis (DKA) (21.2\%), diabetic mellitus foot syndrome (DMFS) (19.5\%) and renal failure (12.7\%). Diabetic emergencies accounted for 39.8\% of all deaths.

Conclusion: Diabetes mellitus is a significant cause of medical admissions in Port-Harcourt. The case mortality is very high especially from acute metabolic causes. There is a need for improved management of diabetes in Nigeria.
\end{abstract}

Keywords: Mortality, Diabetes in-patients, Niger Delta.

\section{NTRODUCTION}

The prevalence of DM is reaching epidemic rates globally and the incidence is estimated at 220 million by the year 2010 (1). In Nigeria, the national prevalence of DM is $2.2 \%$ with a higher prevalence in the urban than in the rural communities (2). The prevalence of DM in Port Harcourt is estimated to be $6.8 \%$ (3).

The main causes of morbidity and mortality in Nigerian diabetes patients include acute metabolic complications, foot ulcers, cardiovascular diseases, cerebrovascular disease and nephropathy $(4,5)$. People with DM have been shown to have higher mortality rates than those without DM though mortality rates depend on the location and the specific group (6). Diabetes is the sixth leading cause of death in the United States of America (7).

DM is also the highest non communicable disease cause of morbidity and mortality in Africa (8). In Port Harcourt, diabetes is the fifth commonest cause of medical deaths (9). Overall, it is estimated that $8-10 \%$ of people over 50 years Worldwide have diabetes, $40 \%$ of whom will die from kidney disease and $60 \%$ from cardiovascular complications (10).

This present study was carried out to determine the current trend of mortality among diabetic admissions at a Nigerian Teaching Hospital.

\section{MATERIALS AND METHODS}

The medical records of patients admitted with DM into the medical wards of the University of Port Harcourt Teaching Hospital (UPTH) were reviewed. The period of review spanned from 1995 to 2004 . The sources of data were the medical records, ward admissions, death registers and death certificates. The information obtained from the records included the age, sex, date of admission and the cause of death. The diagnosis of DM as appropriate in the hospital was based on the World Health Organization criteria (1). The data obtained were analyzed using the Statistical Package for Social Sciences (SPSS). Statistical significance was said to be present if $p \leq 0.05$.

\section{RESULTS}

There were 6,574 medical admissions during the period under review. Of these, $686(10.4 \%)$ were due to DM. There were $428(62.4 \%)$ males and $258(37.6 \%)$ females among the diabetic admissions. The yearly pattern of medical and DM deaths are shown in table 1 . 
Table 1: Yearly distribution of medical and diabetic admissions

\begin{tabular}{|c|c|c|c|c|c|c|}
\hline Year & $\begin{array}{l}\text { Male } \\
\text { medical } \\
\text { admissions }\end{array}$ & $\begin{array}{l}\text { Diabetic } \\
\text { admissions }\end{array}$ & $\begin{array}{l}\text { Female } \\
\text { medical } \\
\text { admissions }\end{array}$ & $\begin{array}{l}\text { Diabetic } \\
\text { admissions }\end{array}$ & $\begin{array}{l}\text { Total } \\
\text { medical } \\
\text { admissions }\end{array}$ & $\begin{array}{l}\text { Total } \\
\text { diabetic } \\
\text { admissions }\end{array}$ \\
\hline 1995 & 215 & 27 & 375 & 24 & 590 & 51 \\
\hline 1996 & 162 & 30 & 274 & 19 & 436 & 49 \\
\hline 1997 & 307 & 36 & 441 & 28 & 748 & 64 \\
\hline 1998 & 315 & 52 & 484 & 30 & 799 & 82 \\
\hline 1999 & 199 & 27 & 381 & 27 & 580 & 54 \\
\hline 2000 & 317 & 53 & 390 & 29 & 707 & 82 \\
\hline 2001 & 302 & 57 & 278 & 20 & 580 & 77 \\
\hline 2002 & 304 & 50 & 321 & 26 & 625 & 76 \\
\hline 2003 & 326 & 52 & 419 & 17 & 745 & 69 \\
\hline 2004 & 354 & 44 & 410 & 38 & 764 & 82 \\
\hline Total & 2801 & 428 & 3773 & 258 & 6574 & 686 \\
\hline
\end{tabular}

The total medical deaths were 1061, of which 118 (11.1\%) were diabetes patients. The highest mortality among the diabetes patients was seen in those aged 51-60 years and this is shown in figure 1 .

Figure 1: Distribution of diabetic by age

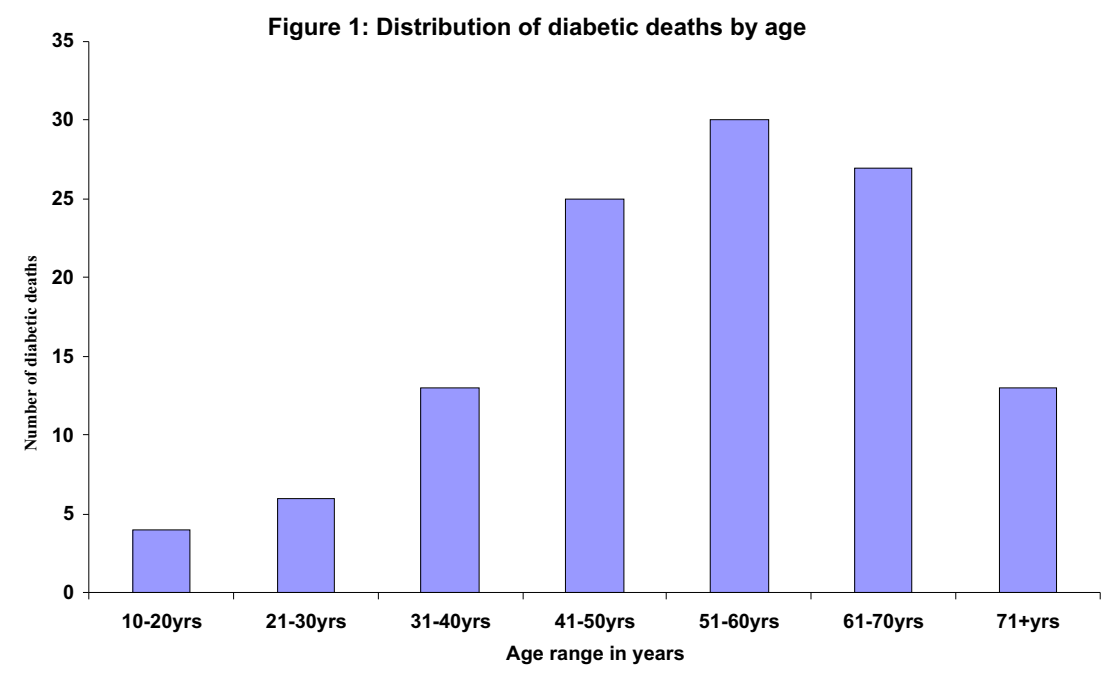

Over $39 \%$ of the deaths resulted from acute diabetic emergencies viz diabetic ketoacidosis (DKA), hyperosmolar non ketotic state (HONKS) and hypoglycaemia. Diabetes foot ulceration was the leading cause of death among the chronic complications of diabetes. The causes of death among the diabetes patients are shown in table 2 .

Table 2: Causes of deaths in diabetes patients

\begin{tabular}{ll}
\hline Disorder & $\boldsymbol{n}(\mathbf{\%})$ \\
\hline DKA & $25(21.2)$ \\
HONKS & $10(8.5)$ \\
Hypoglycaemia & $12(10.2)$ \\
DMFS & $23(19.5)$ \\
Renal failure & $15(12.7)$ \\
Cerebrovascular disease & $12(10.2)$ \\
Septicaemia & $6(5.1)$ \\
Respiratory disease & $6(5.1)$ \\
Others & $9(7.6)$ \\
\hline Total & $\mathbf{1 1 8 ( 1 0 0 )}$ \\
\hline
\end{tabular}

DKA $=$ Diabetic Ketoacidosis, HONKS $=$ Hyperosmolar nonketotic state, DMFS= Diabetes mellitus foot syndrome, 'Others' included malignancies, drug reactions, and hepatic disease, etc.
The overall case fatality for the total medical admissions was $16.1 \%$, while the diabetes case fatality rate was $17.2 \%$. Table 3 shows the yearly case fatality rate based on sex among the diabetes patients. 
Table 3: Case fatality for diabetes mellitus

\begin{tabular}{llllll}
\hline Year & Diabetic admission & $\begin{array}{l}\text { Number of deaths } \\
\text { Male }\end{array}$ & Female & Total & $\begin{array}{l}\text { Case fatality } \\
\text { rates }(\%)\end{array}$ \\
\hline 1995 & 51 & 7 & 7 & 14 & 27.5 \\
1996 & 49 & 6 & 2 & 8 & 16.3 \\
1997 & 64 & 6 & 1 & 7 & 10.9 \\
1998 & 82 & 4 & 5 & 9 & 11.0 \\
1999 & 54 & 4 & 6 & 10 & 18.5 \\
2000 & 82 & 6 & 9 & 15 & 18.3 \\
2001 & 77 & 6 & 4 & 10 & 13.0 \\
2002 & 76 & 12 & 6 & 18 & 23.7 \\
2003 & 69 & 13 & 2 & 15 & 21.7 \\
2004 & 82 & 5 & 7 & 12 & 14.6 \\
\hline
\end{tabular}

The mean and range of diabetic case fatality rates for the 10 -year period were $17.2 \%$ and $10.9-27.5 \%$ respectively. Four hundred and twenty eight $(62.4 \%)$ of the admitted diabetes patients were males, and $69(58.5 \%)$ of the diabetic deaths were males. Two

\section{DISCUSSION}

DM has continued to pose a major health concern in recent times (11). This is supported by the results from this study where over $10 \%$ of medical admissions were due to diabetes. In an earlier review at the same centre, diabetes accounted for about $7.8 \%$ of medical admissions (12). Non- communicable diseases particularly cardiovascular diseases, DM and cancer are the major causes of morbidity and mortality in the developing world and are emerging as an important component of disease burden in developing countries especially in Africa (13-15). The migration and urbanization of populations as well as rapid economic and social change in some cities/ countries have been implicated $(10,11)$. Port Harcourt, the location of the study is situated in the oil- rich Niger Delta region of Nigeria with rapid rate of urbanization and acquisition of some "unhealthy" lifestyles of the industrialized world. These include sedentary occupations, inadequate physical activity associated with an increase in vehicle use, high fat and refined sugar diets, tobacco use and increased drug and alcohol consumption $(11,13,15)$.

Diabetes contributes enormously to the utilization of inpatient hospital services as shown in this study. This finding is in agreement with reports from other centres in Nigeria $(16,17)$.

Although an analysis of the other causes of death was not specifically done, major contributions from the trend observed included chronic renal failure, hypertensive heart disease and stroke. The contributions from such diseases with poor prognosis might explain the much higher overall case fatality for medical admissions (16.1\%) compared to diabetes alone (11.1\%).

The case fatality among the diabetes patients was unacceptability high. Whereas diabetes accounted for $10.4 \%$ of medical admissions, it contributed to $11.1 \%$ of total medical deaths. The majority of the deaths were in the middle-aged and mainly due to preventable causes. Diabetic ketoacidosis, hyperosmolar nonketotic state and hypoglycaemia accounted for almost $40 \%$ of the diabetic deaths. This is similar to reports from other Nigerian and African centres $(16,18,19)$ but much different from reports from industrialized countries with rates from these causes of $3-6 \%(6)$. The high diabetic death rate from these acute and rather preventable causes is a reflection of the poor state of diabetic care services available. A previous study in the same centre revealed that $35.5 \%$ of the diabetic deaths occurred within 24 hours of admission and were mainly due to acute metabolic and hundred and fifty eight (37.6\%) of the diabetic admissions were females while $49(41.5 \%)$ of diabetic deaths were females. The gender difference was not statistically significant $(p>0.05)$.

preventable causes (12). Late presentation to hospital, misdiagnosis, lack of insulin, infections and overall lack of adequate healthcare delivery system are main contributors to acute diabetic deaths $(9,12)$. Good laboratory support, provision of bedside glucometers and ward electrolyte analysers would have enabled frequent monitoring of metabolic changes, with a resultant reduction in mortality. These relatively inexpensive facilities are sadly not routinely available in the emergency rooms and wards of even referral hospitals in many developing countries.

About $19 \%$ of diabetic deaths in this review resulted from diabetic foot ulcers/ gangrene. Several studies have emphasized the burden of diabetic foot syndrome in Nigeria (20-22). The main precipitating factor is often an infection from a minor trauma to an insensitive foot due to diabetic neuropathy (23-25). Deaths from diabetic ulceration can be reduced with good diabetes foot care services and education (24).

Diabetic nephropathy with progression to end stage kidney disease is a common complication of diabetes (10). It is not surprising therefore that renal failure contributed to about $12 \%$ of the diabetic deaths in this study. This is rather disturbing in view of the relative lack of facilities for renal replacement therapy in this part of the world. Diabetes often co-exists with other potent cardiovascular risk factors especially hypertension, thus increasing the risk of early death from cardiovascular cause by about three-fold $(10,26)$. Diabetes and hypertension together account for 50 to $60 \%$ of people on dialysis worldwide (10). Exposure to nephrotoxic agents in industrialized cities like Port Harcourt may also contribute to progression of kidney damage and resultant morbidity and mortality (26).

Cerebrovascular disease accounted for about $10 \%$ of diabetic deaths. DM together with the other components of the metabolic syndrome are major risk factors to cerebrovascular disease $(3,7,18)$. It is also generally known that cerebrovascular disease is a major cause of death among blacks $(7,18)$. This is the trend globally as DM and the other components of the metabolic syndrome are related to urbanization and westernization with associated transition to 'modern' lifestyle of the industrialized world (11).

Death from ischaemic heart disease was rather uncommon in this review contrary to the scenario in the industrialized countries and supports previously published data (27). However, since autopsy reports on diabetes related deaths were not reviewed, some complications may have been missed. Ischaemic heart 
disease in the African remains relatively uncommon although it is presently on the increase in cities like Port Harcourt with high rates of industrialization (28).

\section{CONCLUSION AND RECOMMENDATIONS}

This study has shown that many diabetes patients die from preventable and/ or treatable causes. Possible reasons for this pattern of mortality include inadequate diabetes care services, poverty and lack of diabetes education. This report has brought to the fore the need for DM education. The increasing burden of diabetes is more so, in an environment of limited resources therefore, primary prevention must be the cornerstone of any diabetes policy in Nigeria and Africa in general.

\section{REFERENCES}

1. Amos AF, McCarthy DJ, Zimmet P. The rising global burden of diabetes and its complications: Estimates and projections to the year 2010. 1997; 14:S1-S5.

2. Akinkugbe OO. Non-communicable Diseases in Nigeria. Final report of a national survey; Federal ministry of Health and Social Services, 1997.

3. Nyenwe EA, Odia OJ, Ihekwaba AE, Ojule A, Babatunde S. Type 2 Diabetes in adult Nigerians: a study of its prevalence and risk factors in Port Harcourt, Nigeria. Diabetes Res Clin Pract, 2003; 62: 177-185.

4. Chukwak EK, Puepet FH, Malu AO, Ohwovoriole AE. Morbidity and mortality study of Diabetes admissions in Jos University Teaching Hospital. Diabetes International, 1999; 9: 76-77.

5. Adetuyibi A. Diabetes in the Nigerian African- review of long term complications. Trop Geogr Med, 1976; 28: 155159.

6. Fuller JH. Mortality trends and causes of death in diabetes patients. Diabetes and metabolism, 1993; 13: 96-99.

7. Olefsky JM. Prospects for research in Diabetes mellitus. JAMA, 2000; 285: 628-630.

8. Onen C. Diabetes morbidity and mortality in Botswana: a retrospective analysis of hospital based data on diabetic patients, 1980-1994. International Diabetes Digest, 1998; 13:96-99.

9. Odia OJ, Wokoma FS. Mortality pattern in the medical wards of a Nigerian Teaching Hospital. Orient J Med, 1992; 4: 96100.

10. Dirks J, Robinson S. Preventing vascular diseases in the emerging world: a multidisciplinary approach. Diabetes voice, 2006; 51:45-46.
11. Mohan V, Pradeepa R. Epidemics of type 2 diabetes in developing nations. Current medical literature: Diabetes, 2004; 21: 69-78.

12. Dagogo-Jack S. Diabetes in-patient mortality in Nigeria. Practical Diabetes Digest, 1991;2(3): 117-119.

13. Bory J, Raffin S. Preventing non- communicable diseases: An integrated community approach. Diabetes Voice, 2006; 51: 41-43.

14. Kadiri S. Tackling cardiovascular disease in Africa. BMJ, 2005; 331:711-712

15. Valentin B. Non-communicable disease- a new dilemma for Africa. African Health, 2005; 27: 3.

16. Ogbera AO, Ohwovoriole AE, Soyebi O. Case fatality among diabetic in-patients. Journal of Clinical Sciences, 2002; 2(1): $18-21$.

17. Onwubere BJC. Review of admission into the medical wards of the University of Nigeria Teaching Hospital, Enugu. Nigerian Journal of Internal Medicine, 1999; 2: 59-62.

18. Ahmed AM, Ahmed NH, Abdella ME. Pattern of Hospital mortality among diabetic patients in Sudan. Practical Diabetes International, 2000; 17: 41-44.

19. Corrigan CB, Ahren B. Ten years' experience of a diabetes clinic in northern Tanzania. East Afr Med J, 1968; 45: 89-90.

20. Ogbera AO, Ohwovoriole AE. The economic cost of diabetic foot syndrome. Afr J Endo Metab, 2003; 4: 59-63.

21. Unachukwu CN, Obunge OK, Odia OJ. The Bacteriology of Diabetic Foot Ulceration in Port Harcourt, Nigeria. Nig J Med, 2005; 14(3): 173-176.

22. Lawson EAI, Oyemade GAO, Adetuyibi A. The foot complications in the Nigerian diabetic patients. Nig Med J, 1978; 8: 401-403.

23. Unachukwu CN, Babatunde S, Chinenye S. Peripheral Neuropathy and Macro-angiopathy in diabetics with foot ulcers in Port Harcourt, Nigeria. Nigerian Journal of Orthopaedics and Trauma, 2004; 3(2): 214-224.

24. Shaw JE, Boulton AJM. The pathogenesis of diabetic foot problems. Diabetes 1999; 4: 560-588.

25. Gulam-Abbas Z, Archibald LK. Foot complications in diabetic subjects with symptomatic peripheral neuropathy in Dar es Salam, Tanzania. Diabetes International, 2000; 10: 52 57.

26. Alebiosu CO. An update on 'progression promoters' in renal disease. JNatl Med Assoc, 2003; 95: 30-42.

27. Agomuoh DI,Akpa MR, Alasia DD. Echocardiography in the University of Port-Harcourt Teaching Hospital: April 2000 to March 2003. NigJ Med,2006; 15(2).

28. Oli JM, Ikeh VO. Diabetes mellitus and hypertension in an African population. Journal of the Royal College of 